\section{THE IMPLICATIONS OF THE BEHAVIOUR OF PATIENTS IN THE ILLNESS-ROLE ON THE PSYCHOSOCIAL RELATIONSHIP OF PHYSIOTHERAPISTS WITH THEIR PATIENTS}

\section{A J van Rooijen *}

\section{INTRODUCTION}

The aim of patient treatment is to promote a return to health. The World Health Organisation's definition of health entails the concept of "wholeness". Health is a condition of complete physical, mental and social well-being, and not merely one where disease or infirmity is absent ${ }^{1}$.

Good health is a phenomenon both of the mind and body, and the therapist needs expertise and skills in both these areas in order to achieve his/her goals ${ }^{2}$. The question that then arises is, how much training does the physiotherapist receive in the development of mechanisms to treat the "whole" patient and is she taught to deal with her own emotions skillfully enough to help a patient to cope with his illness?

Successful physiotherapy depends not only on physiotherapy techniques, but also on the psychosocial relationships which the therapist develops with his/her patient. This implies an openness to the patient's feelings and emotions, and a recognition that the patient and physiotherapist have similar needs

Raphael stated that the physiotherapist may be the only person in the medical care team with whom the patient spends sufficient time, over a reasonable period, to enable him to talk about his anxieties and fears, his sadness and disappointment, as well as his anger and guilt about what has happened to him $^{3}$.

Man is a complex being, with among others, physiological, cultural, religious and social requirements. The interaction of these qualities with the individual's environment, including people, will determine his behaviour, his reaction to his illness, to health care workers and to his experience of the illness-role.

Lindesmith and Strauss feel that the patient identifies himself by seeing himself from the perspectives of the community of social groups 4 . The physiotherapist must therefore critically evaluate the behaviour of the patient and also the influence of his/her own behaviour on the patient.

The patient's reactions towards his illness-role and the adoption of what is deemed to be acceptablebehaviour, will be determined by society's perspectives. $\mathrm{Pa}$ tients with previous experience of physiotherapy treatment will therefore behave differently from those patients who have no previous exposure. Apart from these complex social influences, the illnessrole will also be influenced by the patient's interpretation of the role of the physiotherapist in the total treatment plan.

Parsons, who examined society's perspectives on the illness-role, reached the following conclusions:

- the patient is exempted from all his social responsibilities

- the patient cannotbecured by personal resolution

- it is expected from the patient to have the desire to be cured

- it is expected from the patient to seek medical help for his illness, as well as to co-operate with the treatment plan

- in the case of a patient with chronic disease, it is expected that the patient will have a desire to function at his optimal level of "health" within his own limits ${ }^{4}$.

In order to adopt a holistic approach, the physiotherapist must critically evaluate the behaviour of the patient and also the influence of his own behaviour on the patient. Pain and illness behaviour are present to some extent in virtually every patient a therapist sees. It must never be overlooked that patients, first and foremost, are people who are entitled to feel and express emotions in different ways. The therapist may find it easier to tolerate the wide range of behaviours that a specific patient may demonstrate, if he considers for a moment what the patient is going through. Negative feelings and behaviour can be expected if the physiotherapist's role is negatively or incorrectly interpreted.

Very often the patient will have difficulty in protecting his self-image while coping with problems associated with the stress of handling the illness. He may then present with a variety of reactions to relieve the stress he is experiencing. According to Kolb, the manner and degree to which these bchaviours are exercised may vary among individuals ${ }^{4}$.

Some patients need few psychological mechanisms in dealing with illness, while others require a host of mechanisms. There are some patients who, even with the use of all their adoptive mechanisms, never come to accept the illness-component of the wellness-illness role ${ }^{4}$.

The physiotherapist should be familiar with the most important patterns and reactions of patients in order to be able to approach the patient correctly and holistically. The combination of assessment tech-

\section{SUMMARY}

In order for the physiotherapist to adopt a holistic approach in the treatment of her patients, it is necessary for her to bear in mind the patient's previous experience of the illness-role. This experience will influence the patient's behaviour in any subsequent illness-role and thus his interpretation of the role of the physiotherapist in the total treatment plan. It follows then that the physiotherapist should critically evaluate the behaviour of her patient in the illness-role while also evaluating the influence of her own behaviour on the patient in order to make treatment effective.

\section{OPSOMMING}

Die pasiënt se gedrag in die siekrol word deur vorige ervaring daarvan en die rol van die fisioterapeut daartydens beïnvloed. Die fisioterapeut moet die gedrag van die pasiënt in die siekrol en haar eie reaksie daarop krities ondersoek om pasiënte in totaliteit te behandel.

niques of behaviours together with the traditional skills of the therapist can produce a very exciting and powerful tool for rehabilitation and on-going good health. The matter-of-fact, crisp, objective appearance of many physiotherapists is often called "professionalism" which may prevent the therapists from being total persons and from treating the whole patient, as it may distance them from their patient $t^{5}$.

Many patients will fear the unknown aspects of their illness, thus experiencing a feeling of expectation, discomfort or anxiety associated with an unknown source of possible danger. Patients of the same sex, age and socio-economic backgrounds may react differently to fear. Their reactions will be influenced by previous experiences of the illness-role, as well as by the patient's emotional maturity. The physiotherapist will find a moderate degree of fear in a patient beneficial for his adjustment to his' treatment plan, because the patient is wary and adjusts more easily. On the contrary, a very frightened patient becomes disorientated and tends to over-react. A fearful patient can be helped by recognising his fear, by answering his questions, and thus his unspoken fears, in a simple manner and by respecting his privacy. This will help the patient to adjust to the changed environment and to changed relationships ${ }^{6}$.

Very often, a patient will have conflicting emotions about seeking medical help and following the advice given to him. This can cause emotional lability because of the co-existence of opposing emotions, attitudes and desires towards his illness. The physiotherapist can, after recognising this behaviour pattern, reassure the patient that conflicting emotions are not uncom- 
mon and may help the patient to vocalise his feelings. Reflexive reassurance is a spontaneous reaction which occurs in the therapist to counteract feelings of anxiety, uncertainty or worry about the circumstances in which the patient finds himself. This response reflects the physiotherapist's attempt to balance the patient's feelings and to calm the patient by using verbal assurances in a tone of voice which is not unlike that of a parent ${ }^{7}$.

Williams however, cautions us to be careful of "the parent trap". This occurs when patients, feeling miserable, turn to us, as if to parents, for sympathy, understanding, comfort and wisdom, in the hope that we can resolve their problems for them ${ }^{2}$.

A deliberate move by the therapist away from the traditional professional "caring-expert-in-charge"-role, to a relationship where the patient is seen as an equal adult who has a problem he is teaching himself to tackle and cope with, must be made. It must be expected of a patient to take responsibility for his own share of the effort and to make his own decisions; only then can a patient return to normal behaviour.

Suspicious and hostile patients are difficult to handle. The physiotherapist may perceive such a patient as irritable, sarcastic, demanding, critical, uncompliant or quarrelsome. It is important to remember that when a patient directs anger at the therapist, he is usually angry at what the therapist represents, namely health and the health care system, both of which he may feel have betrayed him $^{5}$. The physiotherapist may feel threatened by the hostile behaviour of the patient, since this behaviour endangers the therapist's position of authority over the patient. This can lead to transferral of negative feelings towards the patient, especially through the body-language of the therapist. The patient must be encouraged to verbalise his hostile feelings in order to preserve his self-esteem. The physiotherapist must learn to cope with this type of hostility and not to over-react. Arguing is of no benefit; what is needed is understanding and a willingness to share ${ }^{6}$.

A patient may react to the illness-role by taking on a role suitable to earlier stages of development. These could include withdrawal from all responsibility, an inability to feed himself, wilfulness and changed inter-personal relationships. He will demonstrate this behaviour because it is easier for him to regress to an earlier stage of development than to adapt to the stressful situation in the illness-role. This reaction can be a natural one, because it can promote the healing process, for example, when a post-operative patient allows the health care workers to turn him on the first post-operative day. In the early days fol- lowing trauma, the patient receives intensive medical, surgical and physiotherapeutic intervention aimed at preventing further complications and if possible, restoring function. The focus of rehabilitation is on the patient's physical needs. It wili be difficult for the patient to understand what is happening to him, even if he has had the nature and extent of his injuries explained to him. He may experience shock, denial, numbness and despair. Here the physiotherapist has a vital role to play in facilitating his/her patient's transition from the well- to the illness-role by providing hope, counselling and support ${ }^{6}$. Therapists must encourage their patients to take part in the treatment. Every successful attempt must be encouraged and praised, but care should be taken not to expect too much from the patients.

Depression is a major problem with most patients in that they feel trapped in the illness-role. Feelings of sorrow, inferiority and loss of the joy of life are normal human reactions to being ill. Depression may also set in after a period of anxiety and distress. The patient may then feel that no-one understands him or cares about what is happening to him. By recognising these feelings in the patient, the physiotherapist can help the patient to feel that he is accepted. Physical contact through the light touch of an arm, a shoulder or a hand can show the patient that the physiotherapist cares about him and accepts him as he is. Exercise programmes have a therapeutic effect on the depressed patient as they allow him to unload his pent-up stress or tension in a socially-acceptable manner. Williams states that the patient's confidence and self-pride must be rebuilt by constant praise and every achievements should be rewarded ${ }^{2}$. This process should be structured in very small steps, preferably combined with lots of fun and laughter.

The benefits of humour have been accepted throughout human history, for example in Proverbs 17:22, "A cheerful heart is a good medicine, but a downcast spirit dries up the bones". Robert Burton, Plato and Freud also wrote about laughter. Success with humour is based on the personality of and the relationship between the therapist and the patient involved. Humour and la ughter can be useful in helping a patient to balance a stressful situation by focusing on a less serious aspect of it. Timing of humour, receptiveness of the patient and the conlext of the humour are all factors that must be evaluated to determine if humour and laughter are appropriate in a given situation. lnappropriatehumourcan result in hurt feelings, anxiety, hostility and embarrassment.

\section{CONCLUSIONS}

Alexander said that the most disturbing emotion which the physintlerapist will have to cope with is anger, which is often provoked by the failure of a patient to respond to treatment, despite devoted and prolonged care ${ }^{9}$. Not only may the anger give rise to fragile and inadequate defences, provoking guilt on the part of the physiotherapist, but what may be worse, is that this anger may be communicated to the patient.

It is important to remember that the physiotherapist is human, and is allowed to feel anger at the health care system, the patient and at himself. A balance must be kept by recognising his/her own stress and by finding ways to deal with stress as it occurs. Only then can the physiotherapist have a positive impact on the patient's ability to cope with his stress in the illnessrole. Perhaps the greatest contribution that our profession will have to make in this increasingly technological age, will be the hands-on caring for the individual.

As Weinberg says: "Successful physical therapy depends not only on physiotherapy techniques, but upon the psycho-social relationships which the therapist develops with the patient ${ }^{\prime \prime 10}$.

\section{References}

1. Glauber KA. Expanding Fhysiotherapy. South African Journal of Physiotherupy 1976;32(4):2-6.

2. Williams J. Illness behavior to wellness behaviour. Physiotherapy.

3. Raphael B. Crisis and the physiotherapist. Australian Journal of Physiotherapy 1975;21(2):51-56.

4. Lambert VL, Lambert C.E. Psychosocial care of the physically ill. New Jersey: Prentice-Hall 1985;3-7,13.

5. Snyder R. Coping: You and your patient with cancer. Clinical Management 1992;12(4):64-69.

6. Ateer M. Some aspects of grief in physiotherapy. Physiotherapy 1989;75(1):55-58.

7. Morse J et al. Beyond empathy: expanding expressions of caring. Journal of Advanced Nursing.

8. Davidhizar R, Bowen M. The dynamics of laughter. Archives of Psychiatric Nursing.

9. Alexander DA. Yes, but what about the patient? Physiotherapy 1973;59(12):391-393.

10. Weinberg L. Psychosocial relationships, training and the attitudes with reference to physiotherapists. South African Journal of Physiotherapy 1977;33(4):14-15.

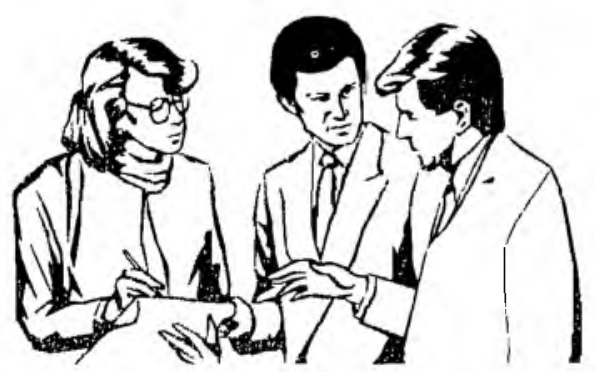

